Fetal Diagnosis and Therapy
Fetal Diagn Ther 2011;30:70-72

DOI: $\underline{10.1159 / 000326300}$
Received: October 28, 2010

Accepted after revision: February 22, 2011

Published online: April 21, 2011

\title{
Prenatally Evolving Ectopia Cordis with Successful Surgical Treatment
}

\author{
Paweł Sadłecki ${ }^{a}$ Michał Krekora ${ }^{\text {b, e }}$ Grzegorz Krasomski ${ }^{b}$ \\ Małgorzata Walentowicz-Sadłecka ${ }^{\text {a }}$ Marek Grabiec $^{\text {a Jacek Moll }}$ \\ Maria Respondek-Liberskad, e \\ a Department of Obstetrics and Gynecology, Collegium Medicum in Bydgoszcz, Nicolaus Copernicus University \\ of Torun, Bydgoszcz, ${ }^{\text {b }}$ Department of Obstetrics and Gynecology, ${ }^{C}$ Cardiac Surgery Department, \\ ${ }^{\mathrm{d}}$ Department for Diagnoses and Prevention of Fetal Malformations, Research Institute Polish Mother's Memorial \\ Hospital and ${ }^{\mathrm{e}}$ Medical University of Lodz, Lodz, Poland
}

\section{Key Words}

Ectopia cordis · Evolution before delivery •

Surgical treatment

\begin{abstract}
Ectopia cordis (EC) is a rare malformation due to failure of maturation of the midline mesodermal components of the chest and abdomen. It can be defined as a complete or partial displacement of the heart outside the thoracic cavity. It comprises $0.1 \%$ of congenital heart diseases. Common cardiac anomalies associated with EC are ventricular septal defect, atrial septal defect, and tetralogy of Fallot. EC and additional anomalies usually lead to intrauterine death. The possibility and efficacy of surgery in a surviving neonate depends on the degree of EC, coexisting congenital heart defects and extracardiac malformations. We present a case of prenatally diagnosed isolated EC diagnosed in the first half of pregnancy. After counseling, the patient decided to continue her pregnancy which ended with a newborn baby discharged from the hospital after cardiac surgery performed just after elective cesarean section.
\end{abstract}

Copyright $\odot 2011$ S. Karger AG, Basel
(C) 2011 S. Karger AG, Basel

1015-3837/11/0301-0070\$38.00/0

Accessible online at:

www.karger.com/fdt

\section{Case Report}

The 28-year-old healthy patient (G1, P0) had no history of congenital anomalies. Screening ultrasound performed at 6 and 10 weeks of pregnancy were described as 'normal'. NT evaluation and nasal bone at gestational week 12 were normal. Subsequent prenatal ultrasonography at gestational week 18 showed omphalocele and ectopic heart located partially outside the thorax. Fetal echocardiography revealed ventricular septal defect and enlargement of the right atrium and ventricle, insufficiency of the tricuspid valve and hypoplastic root of the aorta (fig. 1). The pregnant women was offered cytogenetic evaluation and termination of pregnancy; however, she decided to continue her pregnancy and delivered in a tertiary obstetrical and cardiac center. Fetal echocardiography was performed at gestational weeks 19, 24, 33 and 38 (fig. 2). The cardiovascular profile score was always 10 and did not change during the fetal monitoring. Heart anatomy assessment was similar as in the first echocardiography; however, the position of the fetal heart and size of omphalocele changed: there was an improvement in the fetal atria and 'niche' in the fetal chest and a decrease in size of fetal omphalocele (fig. 3). At gestational week 39, an elective cesarean section was performed: a boy, weighting 3,400 g, was delivered and immediately transferred from the delivery ward to the cardiosurgery theater. Physical and echocardiographic examination pointed out ectopic heart with double outlet tract from the right ventricle, ventricular septal defect and small epigastric omphalocele (fig. 4). The cardiac surgeon performed a single-stage closure of the abdominal defect, displacement of the ectopic heart and banding of the pulmonary artery. The operation succeeded without any complications (fig. 5).

Paweł Sadłecki

Department of Obstetrics and Gynecology, Collegium Medicum in Bydgoszcz Nicolaus Copernicus University in Torun, Ul. Ujejskiego 75

PL-85-168 Bydgoszcz (Poland)

Tel.+48 693529 294, E-Mail pawelsadlecki@wp.pl 


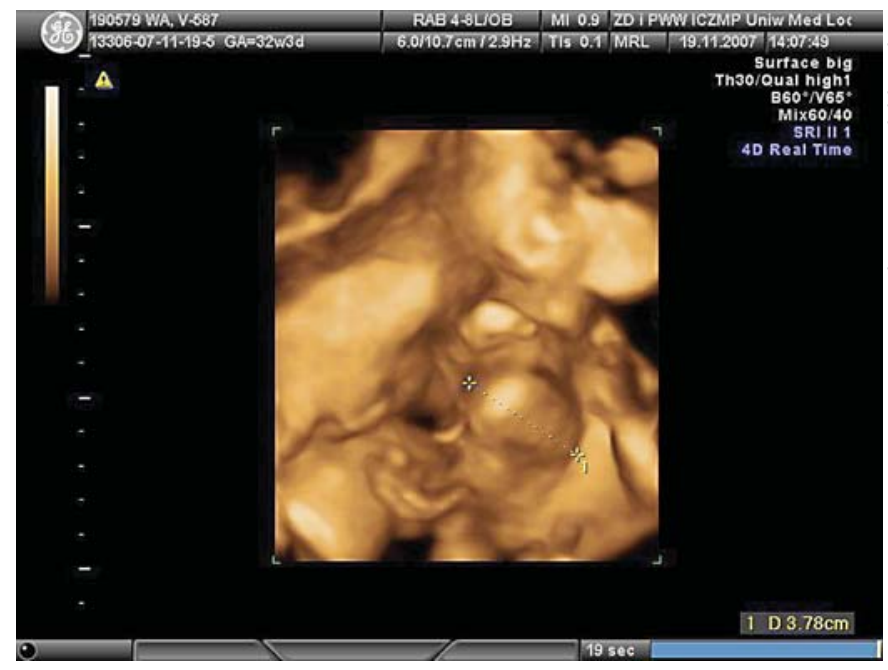

Fig. 1. 3D echocardiography showing the fetal chest at week 33 of pregnancy (heart is seen between plus signs).

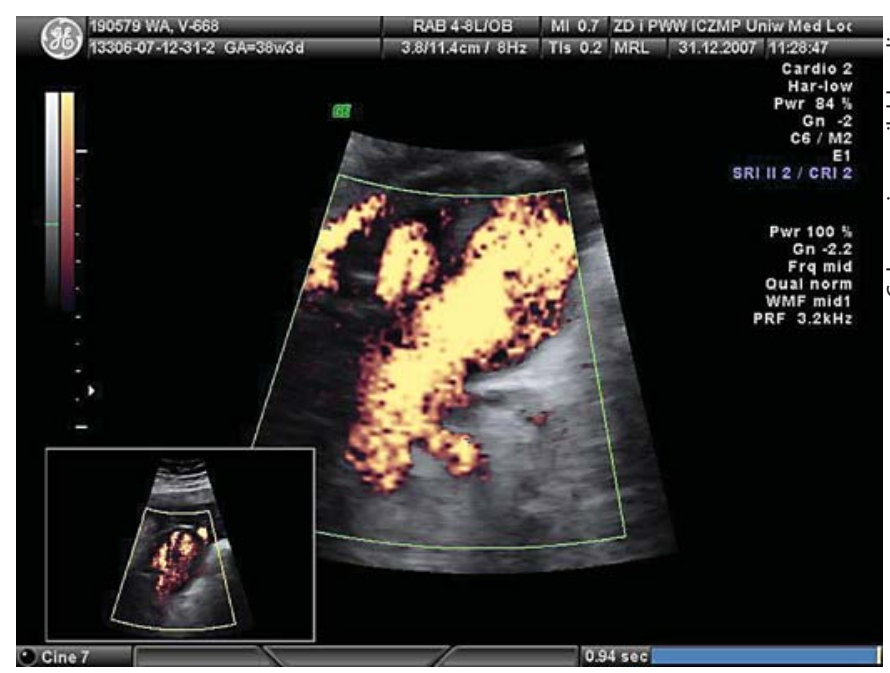

Fig. 3. Right ventricle outflow tract at week 38 of pregnancy.

After 53 days the child was discharged from the hospital. At 6 months of age he was doing fine and was scheduled for final cardiosurgery repair at 10-12 months of age.

\section{Discussion}

Ectopia cordis (EC) is a rare malformation, occurring in 5.5-7.9 per million live births due to failure of maturation of the midline mesodermal components of the chest

Prenatally Evolving EC with Successful

Surgical Treatment

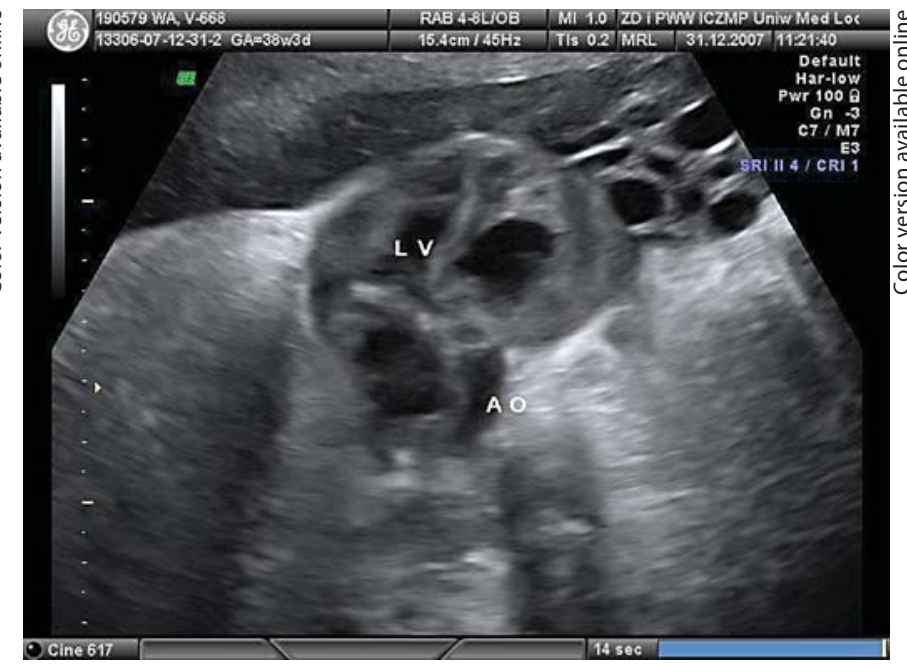

Fig. 2. Ectopic heart located partially outside the thorax (LV, left ventricle; $\mathrm{AO}$, aorta) at week 38 of pregnancy.

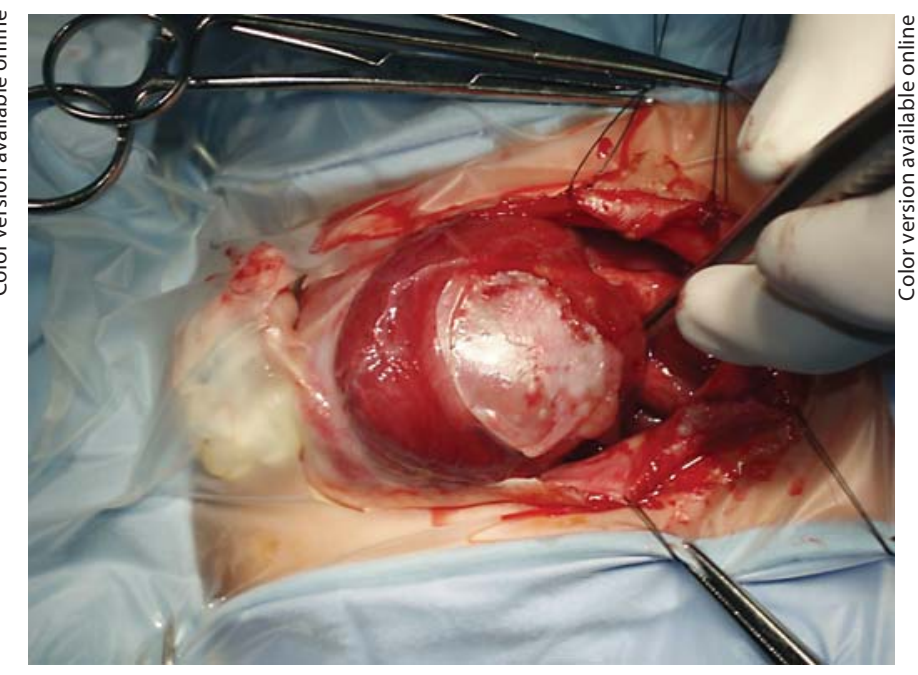

Fig. 4. Ectopic heart before surgical treatment.

and abdomen. It can be defined as a complete or partial displacement of the heart outside the thoracic cavity. EC can be classified into four types according to the cardiac location: thoracic (60\%), abdominal (30\%), thoracoabdominal (7\%) and cervical (3\%) [1]. Ultrasound is the primary diagnostic modality for the diagnosis of fetal anomalies, allowing the detection of complex lesions such as EC at an early stage of gestation. EC comprises $0.1 \%$ of congenital heart diseases. Common cardiac anomalies associated with this malformation are: ventricular septal

Fetal Diagn Ther 2011;30:70-72 


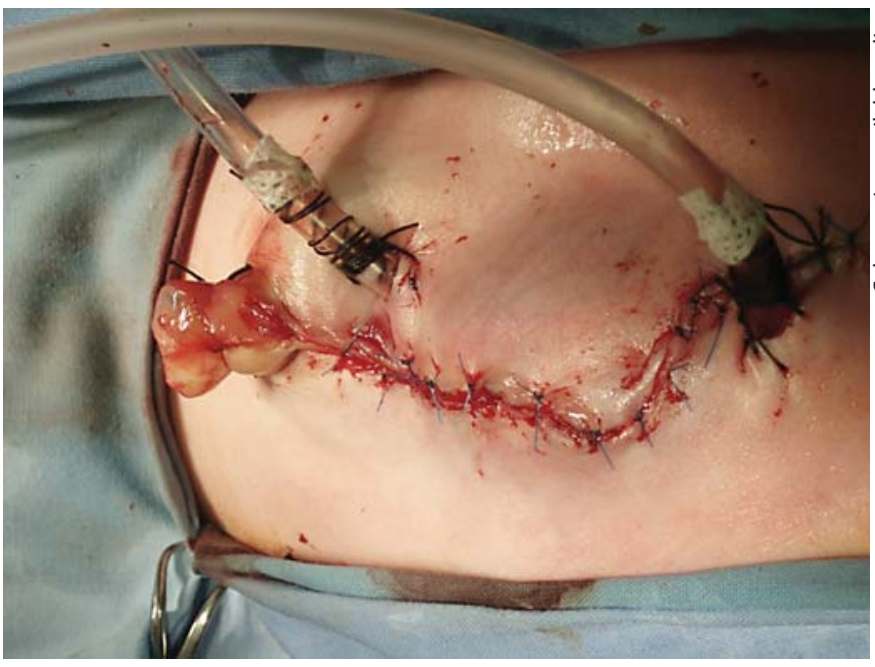

Fig. 5. The patient after surgical treatment.

defect (100\%), atrial septal defect (53\%), and tetralogy of Fallot (20\%) [2]. Extracardiac anomalies associated with EC described in the literature are amniotic band syndrome, diaphragmatic hernia, body stalk syndrome, omphalocele, cleft lip and palate, and skeletal malformations such as kyphosis. EC with sternal cleft, omphalocele and the ventral diaphragmatic hernia raises the possibility of pentalogy of Cantrell (table 1). The defect of the abdominal wall can range from simple diastasis to huge omphalocele with bowel, liver, and heart in the defect covered by a translucent membrane [3].

When several anomalies are present, the fetal prognosis is usually dismal despite normal fetal karyotype and we would consider EC as a lethal anomaly. Despite advances in neonatal cardiac surgery, complete thoracic EC remains a surgical challenge with only few long-term survivors. The possibility and efficacy of surgery in a
Table 1. EC - differential diagnosis

\begin{tabular}{ll}
\hline Pentalogy of Cantrell & $\begin{array}{l}\text { Sternal, pericardial and diaphragmatic } \\
\text { defects, omphalocele }\end{array}$ \\
\hline $\begin{array}{l}\text { Beckwith-Wiedemann } \\
\text { syndrome }\end{array}$ & $\begin{array}{l}\text { Organomegaly, polyhydramnios, } \\
\text { macroglossia, large omphalocele }\end{array}$ \\
\hline $\begin{array}{l}\text { Amniotic band } \\
\text { syndrome }\end{array}$ & $\begin{array}{l}\text { Random defects, constriction rings, } \\
\text { amputations, bands }\end{array}$
\end{tabular}

Limb-body wall complex

Complex-looking mass entangled with membrane, limb anomalies, spinal anomalies

surviving neonate depends on the degree of EC and coexisting congenital heart defects and/or absence of extracardiac malformations. The aims of surgical treatment are to provide a soft tissue cover of the heart, to reduce the heart into the thoracic cavity, palliation or repair of intracardiac anomalies and reconstruction of the chest wall. The major peri- and postoperative problem is avoidance of high abdominal and intrathoracic pressures occurring because of repositioning of the heart in a small thorax [4].

During fetal life the EC may change with time, as presented in our case: there was significant regression of the huge omphalocele at mid-gestation compared with the end of pregnancy; a similar positive evaluation was described by Zidere and Allan [5].

The presented case is important in two ways: firstly, it showed the possibility of the fetal heart changing position during pregnancy, and secondly that immediate postnatal surgery might be planned based on prenatal findings. Detailed fetal echocardiography has helped in counseling and choosing the optimal term, place and method of delivery and the optimal postnatal care in this unique case, originally presented to the parents as a lethal malformation.

\section{References}

Morales JM, Patel SG, Duff JA, Villareal RL, Simpson JW: Ectopia cordis and other midline defects. Ann Thorac Surg 2000;70:111114.

2 Repondek-Liberska M, Janiak K, Wloch A: Fetal echocardiography in ectopia cordis. Pediatr Cardiol 2000;21:249-252.

3 Gimenez-Scherer JA, Davies BR, ResendizMoran MA, Duran-Padilla MA: Abdominal wall defects: autopsy findings of distinct groups suggest different pathogenetic mechanisms. Pediatr Dev Pathol 2009;12:22-27.
4 Serrano Gomez SG, Bermulez Sosa MT, Palma Hernandez E, del Castillo Salceda LF, Pinzon Muslera O, Hernandez Cortes B, Mendez Machado G: Ectopia cordis: multidisciplinary approach with successful result (in Spanish). Ginecol Obstet Mex 2006;74: 439-443.

$\checkmark 5$ Zidere V, Allan LD: Changing findings in pentalogy of Cantrell in fetal life. Ultrasound Obstet Gynecol 2008;32:835-837. 